\title{
Short Communication: Malic Acid Does Not Promote Vaccenic Acid Accumulation in Mixed Ruminal Fluid with Fractionated Fish Oil by a Rumen-Simulation Technique
}

\author{
L. Liu, J. Q. Wang, ${ }^{1}$ D. P. Bu, S. J. Liu, S. Liang, H. Y. Wei, L. Y. Zhou, and K. L. Liu \\ State Key Laboratory of Animal Nutrition, Institute of Animal Science, Chinese Academy of Agricultural Sciences, Beijing, 100094, P. R. China
}

\begin{abstract}
The objective of this study was to determine whether malic acid could promote the accumulation of vaccenic acid in the rumen. The control diet was composed of a 65:35 ratio of forage to concentrate with 1\% (dry matter basis) added fractionated fish oil (rich in docosahexaenoic acid), and treatment diets consisted of the control diet with added malic acid to achieve final concentrations of $10 \mathrm{~m} M$ (treatment 1) and $20 \mathrm{~m} M$ (treatment 2), respectively. The experiment was conducted with rumen-simulation equipment (Rusitec) consisting of 9 fermenters. Each treatment included 3 fermenters as replicates. After $7 \mathrm{~d}$ of incubation, concentrations of vaccenic acid from treatment 1 (4.38\% fatty acids) and treatment $2(4.46 \%$ fatty acids) were similar to that of the control treatment $(4.51 \%$ fatty acids). The disappearance of docosahexaenoic acid was not different among the control, treatment 1 , or treatment 2 . These data indicated that malic acid did not promote the accumulation of vaccenic acid in ruminal fluid.
\end{abstract}

Key words: biohydrogenation, fractionated fish oil, malic acid, rumen-simulation technique

Most of the cis-9, trans-11 isomer of conjugated linoleic acid (CLA) in milk fat, which is well documented to be beneficial to human health (Belury, 1995; Parodi, 1997), is derived from vaccenic acid (VA; trans-11 C18:1) via $\Delta^{9}$-desaturase in the ruminant mammary gland (Piperova et al., 2002). Turpeinen et al. (2002) further suggested that VA has potential benefits for human health because it could form cis-9, trans-11 CLA by the action of $\Delta^{9}$-desaturase in the tissues of humans. Many researchers have been interested in how to increase the content of VA in the rumen, because it could enhance both the cis-9, trans-11 CLA and VA content in the ruminant product, both of which benefit human health. Some research has shown that the ad-

Received January 1, 2008.

Accepted May 10, 2008.

${ }^{1}$ Corresponding author: jqwangcaas@gmail.com dition of fish oil, which is rich in docosahexaenoic acid (DHA), in diets could increase the content of VA in the rumen more than could plant oils (Scollan et al., 2001; Shingfield et al., 2003). The present consensus on the steps in the biohydrogenation (BH) of a-linolenic acid, linoleic acid, and $\mathrm{Y}$-linolenic acid is that the cis-12 double bond will first undergo isomerization, then the cis-9 double bond will be hydrogenated, and finally, the cis-15 and cis- 6 double bonds will be hydrogenated to VA, respectively. This leaves VA as the penultimate product subsequent to the formation of stearic acid, a metabolic step that involves the transfer of $2 \mathrm{H}$ (hydrogen ions) to the trans double bond. In this pathway, flavin acts as an endogenous donor, transferring $\mathrm{H}$ to a-tocopherolquinol in the final reduction step of VA to stearic acid by using the reduced nicotinamide adenine dinucleotide (NADH) pathway (Harfoot and Hazlewood, 1997). Furthermore, the extent of $\mathrm{BH}$ of polyunsaturated fatty acids (PUFA) in the rumen is correlative with the rumen environment (e.g., $\mathrm{pH}$; AbuGhazaleh et al., 2005). AbuGhazaleh and Jacobson (2007) observed a greater concentration of trans C18:1 under a higher pH condition. Similarly, Martin and Jenkins (2002) noticed less trans C18:1 FA formation at culture $\mathrm{pH}$ 5.5 compared with culture $\mathrm{pH}$ 6.5.

Malic acid is a key intermediate in the succinatepropionate pathway. In this pathway, malic acid might act as an electron sink for $\mathrm{H}$ before the dehydration of malic acid to fumarate (Newbold et al., 2005). Previous studies showed that the addition of some organic acids, including aspartate, malate, and fumarate, in the diet could decrease methane production in the rumen (García-Martínez et al., 2005; Newbold et al., 2005). These organic acids may act as electron sinks, competing with methanogens for the available $\mathrm{H}$ (Callaway and Martin, 1996; Ungerfeld et al., 2003). Newbold et al. (2005) calculated that approximately $44 \%$ of the $\mathrm{H}$ was used by fumarate in the rumen before being used for $\mathrm{CH}_{4}$ formation. Many studies have been conducted to evaluate the effect of malic acid addition on rumen fermentation and rumen microbial populations. Addition of malate in the diet could affect rumen fermenta- 
Table 1. Ingredient and chemical composition content of the basal diet

\begin{tabular}{lc}
\hline Item & $\begin{array}{c}\text { Content } \\
\text { (\% of DM) }\end{array}$ \\
\hline Ingredient & \\
Alfalfa hay & 23.0 \\
Chinese wild rye & 42.0 \\
Corn & 16.5 \\
Wheat bran & 6.0 \\
Soybean meal & 8.0 \\
Cottonseed meal & 2.0 \\
Calcium carbonate & 0.6 \\
Calcium phosphate, dibasic & 0.6 \\
Sodium chloride & 0.3 \\
Fractionated fish oil ${ }^{1}$ & 1.0 \\
Chemical composition of total diet (\% of DM) & \\
CP & 14.22 \\
Ether extract & 4.02 \\
Net energy (MJ/kg) & 4.98 \\
NDF & 49.75 \\
ADF & 30.43 \\
Ca & 1.2 \\
P & 0.8 \\
\hline
\end{tabular}

${ }^{1}$ Fractionated fish oil was dissolved in ethanol before being added directly to the fermenter.

tion by increasing VFA concentration, increasing $\mathrm{pH}$, and changing the microbial populations and activity (Carro and Ranilla, 2003; Gomez et al., 2005).

Thus, we hypothesized that supplementing malic acid in the rumen might promote VA accumulation. We speculated that this might be via some potential mechanism if it was similar to what we expected. One potential mechanism is that malic acid might act as a competitive inhibitor for hydrogenation of PUFA or might act as an electron sink, disturbing the electron transfer in the BH of PUFA. Another is that malic acid might affect rumen fermentation, which then affects the BH of PUFA. Thus, the objective of this study was to evaluate whether malic acid could promote the accumulation of VA in the rumen.

Malic acid (99\% purity) was purchased from SigmaAldrich Chemical Company (St. Louis, MO). Fractionated fish oil (rich in DHA, 85\% purity) was purchased from Hebei Haiyuan Chemical Company (Haiyuan City, Heibei Province, P. R. China). Before the experiment was conducted, $40 \mathrm{~g}$ of fractionated fish oil was dissolved in $200 \mathrm{~mL}$ of ethanol $(0.2 \mathrm{~g}$ in $1 \mathrm{~mL})$ and stored at $4^{\circ} \mathrm{C}$. Two ruminally fistulated lactating Holstein dairy cows were fed a TMR composed of $50 \%$ concentrate mix [composed mainly of corn (26\%), wheat bran (4.5\%), soybean meal (11\%), cottonseed meal $(4 \%)$, and rapeseed meal (2\%), with the other components being minerals and salt], $25 \%$ corn silage, and $25 \%$ alfalfa hay (on a DM basis), and inoculum fluid was drawn with a vacuum pump $2 \mathrm{~h}$ after the morning feeding and strained through 4 layers of cheesecloth. Inoculum fluid obtained from the 2 cows was mixed in a bottle and transferred to the laboratory under anaerobic conditions at $39^{\circ} \mathrm{C}$ and then distributed to each fermenter within $20 \mathrm{~min}$. The control diets consisted of a 65:35 ratio of forage to concentrate with $1 \%$ (on a DM basis) fractionated fish oil (high-DHA diet; Table 1). The treatment diets consisted of the control with malic acid added to achieve a final concentration of $10 \mathrm{~m} M$ (Trt1) and $20 \mathrm{~m} M$ (Trt2), respectively. Each treatment contained 3 fermenters as replicates. The experimental period consisted of $6 \mathrm{~d}$ for adaption and $1 \mathrm{~d}$ for sampling, and was repeated 2 times within a 3 -wk interval.

Each fermenter, with an effective volume of 2,000 $\mathrm{mL}$, was filled with $800 \mathrm{~mL}$ of inoculum fluid and 800 $\mathrm{mL}$ of prewarmed buffer according to the method of McDougall (1948). The fermenters, which were maintained at $39^{\circ} \mathrm{C}$, were mixed constantly at $15 \mathrm{rpm}$ via an impeller stirrer and purged with $\mathrm{CO}_{2}$ gas (99\% purity). The $\mathrm{pH}$ of each fermenter was regulated by addition of McDougall's buffer $\left(9.8 \mathrm{~g}\right.$ of $\mathrm{NaHCO}_{3}, 0.57 \mathrm{~g}$ of $\mathrm{KCl}$, $9.3 \mathrm{~g}$ of $\mathrm{Na}_{2} \mathrm{HPO}_{4} \cdot 12 \mathrm{H}_{2} \mathrm{O}, 0.47 \mathrm{~g}$ of $\mathrm{NaCl}, 0.12 \mathrm{~g}$ of $\mathrm{MgSO}_{4} \cdot 7 \mathrm{H}_{2} \mathrm{O}$, and $0.04 \mathrm{~g}$ of $\mathrm{CaCl}_{2}$ dissolved in 1,000 $\mathrm{mL}$ of distilled water and adjusted to $\mathrm{pH} 6.9$ using $\mathrm{CO}_{2}$; McDougall, 1948) through a tube connected to a pump at a continuous rate of $0.78 \mathrm{~mL} / \mathrm{min}$. A total of $40 \mathrm{~g}$ of substrate was placed into each fermenter daily in 2 equal portions, at 0800 and $2000 \mathrm{~h}$. After replenishing diets in the fermenters daily, fractionated fish oil in 1 $\mathrm{mL}$ of ethanol was added directly to all the fermenters, and 2.68 and $5.36 \mathrm{~g}$ of malic acid was added to the Trt1 and Trt2 fermenters, respectively. To maintain anaerobic conditions, all fermenters were purged with $\mathrm{CO}_{2}$ gas for $3 \mathrm{~min}$.

On the last day of the experiment, 3 aliquots of a 10-mL sample (a mixture of liquid and solids) from each fermenter were collected with an injection syringe from the $\mathrm{CO}_{2}$ airscoop at $0 \mathrm{~h}$ (before the morning feeding) and 3,6, and $9 \mathrm{~h}$ later and immediately stored at $-20^{\circ} \mathrm{C}$ until analysis. For extraction of fatty acids (FA) from the culture fluid, chloroform:methanol (2:1, vol/ vol) was prepared (Kramer and Zhou, 2001). The chloroform solution containing the FA was dried under $\mathrm{N}_{2}$, and the FA in the culture fluid were then methylated according to the method of Kramer et al. (1997). Separation of the individual FA in the samples was achieved by using a gas chromatograph (model 6890, Series II, Hewlett-Packard Co., Avondale, PA) fitted with a flame-ionization detector and a fused-silica SP2560 capillary column $(100 \mathrm{~m} \times 0.25 \mathrm{~mm}$ i.d., $0.20 \mu \mathrm{m}$ film thickness; Supelco Inc., Bellefonte, PA). Detailed procedures and detection conditions for FA analysis were described previously (Bu et al., 2007). Heptadecanoic acid was used as a quantitative FFA internal standard. Each peak was identified by comparison with standard 
Table 2. Composition of fatty acids of the basal diet and fractionated fish oil fed to the artificial rumen (Rusitec)

\begin{tabular}{lcc}
\hline Fatty acid profile & $\begin{array}{c}\text { Basal } \\
\operatorname{diet}^{1}(\%)\end{array}$ & $\begin{array}{c}\text { Fractionated } \\
\text { fish oil (\%) }\end{array}$ \\
\hline C16:0 & 12.3 & $\mathrm{ND}^{2}$ \\
C18:0 & 3.8 & $\mathrm{ND}$ \\
trans-11 C18:1 (vaccenic acid) & $\mathrm{ND}$ & $\mathrm{ND}$ \\
cis-9 C18:1 & 10.5 & $\mathrm{ND}$ \\
cis-9, cis-12 C18:2 & 25.2 & 0.17 \\
C18:3 & 12.5 & 0.08 \\
c20:0 & 0.7 & $\mathrm{ND}$ \\
C20 90 trans-11 C18:2 (conjugated linoleic acid) & 0.2 & $\mathrm{ND}$ \\
C20:5 (eicosapentaenoic acid) & 0.5 & 0.21 \\
C24:0 & $\mathrm{ND}$ & 0.10 \\
C22:5 & $\mathrm{ND}$ & $\mathrm{ND}$ \\
C22:6 (docosahexaenoic acid) & 3.1 & 7.16 \\
Other fatty acids & 30.0 & 80.93 \\
\hline
\end{tabular}

${ }^{1}$ Basal diet included concentrate, forage, and fractionated fish oil.

${ }^{2} \mathrm{ND}=$ not detected or detected at $<0.01$.

FA methyl esters (FAME; Nu-Chek Prep, Elysian, MN; Matreya, Pleasant Gap, PA; and 37-Component FAME mix, Supelco, Bellefonte, PA). The percentage of each FA was calculated by dividing the area under the FA peak (minus the area under the peak for heptadecanoic acid) by the sum of the areas under all the reported peaks. All results were reported as the percentage of FAME. The data were analyzed by using PROC MIXED of SAS, version 8.2 (SAS Institute Inc., Cary, NC). Each fermenter was defined as a random effect, whereas treatments and sampling times were defined as fixed effects. For statistical analysis of the ruminal fluid, treatment, sampling time, and the interaction of sampling time $\times$ treatment were defined as fixed effects and analyzed by using repeated measures. Least squares means and pooled SEM were reported for all data. Significance was set at $P<0.05$.

If malic acid were able to compete for $\mathrm{H}$ with $\mathrm{BH}$ of PUFA at the step from VA to stearic acid or if malic acid acted as an electron sink, disturbing the electron transfer of $\mathrm{BH}$ in the NADH pathway when incubated in mixed ruminal fluid with high-DHA diets, this would lead to a decreased extent of BH of FA, an increased accumulation of VA, and a decreased stearic acid concentration. However, after $6 \mathrm{~d}$ of adaption, the concentrations of VA among the control (4.51\% FAME), Trt1 (4.38\% FAME), and Trt2 (4.46\% FAME) cultures were not different $(P>0.05)$. Addition of malic acid did not change the concentration of stearic acid in the cultures. Moreover, the disappearance of DHA was similar among the control (60.5\%), Trt1 (62.7\%), and Trt2 (56.9\%) cultures by calculation based on Tables 2 and 3 . In addition, concentrations of each FA in the culture fluid did not differ with sampling time, except for VA $(P<0.01)$, cis-9, cis-12 C18:2 $(P<0.01)$, and DHA
$(P<0.01)$. The interaction of treatment and sampling time was not different $(P>0.05)$, except for $\mathrm{C} 18: 0$ and DHA.

Previously, AbuGhazaleh and Jenkins (2004) concluded that DHA or its derivatives promoted VA accumulation, possibly by inhibiting the reductase enzymes from ruminal microorganisms that were responsible for the terminal hydrogenation of VA to stearic acid. However, results obtained from the present study indicated that addition of malic acid in ruminal fluid did not promote the accumulation of VA. Harfoot and Hazlewood (1997) considered that although unsaturated FA were known to inhibit methanogenesis in the rumen, they did so at millimolar concentrations, which are too low to serve as major competitors for $\mathrm{H}$. We considered that the $\mathrm{H}$ used by malic acid may not affect the $\mathrm{H}$ that would be used by unsaturated FA, because the amount of $\mathrm{H}$ in the rumen used by unsaturated FA is very limited (Jenkins et al., 2008). Malic acid may possibly act as an electron sink that does not disturb the electron transfer of $\mathrm{BH}$ of FA in the $\mathrm{NADH}$ pathway. In the current study, addition of malic acid did not affect the concentration of FA. This was inconsistent with our theoretical deduction. The change in rumen $\mathrm{pH}$ has been shown to have a negative effect on microbial populations (Martin et al., 2002), particularly on the growth of cellulolytic bacteria, which are indeed the main rumen biohydrogenating bacteria (Harfoot and Hazlewood, 1997). Latham et al. (1972) found that switching lactating dairy cows from a highforage to a low-forage diet, which promotes low rumen $\mathrm{pH}$, resulted in lower levels of lipolytic activity and $\mathrm{BH}$ of unsaturated FA in ruminal fluid, as measured by an in vitro experiment. Accordingly, the addition of malic acid could have affected the concentration of FA. 
Table 3. Fatty acid profiles (fatty acids as a \% of fatty acid methyl esters) in the Rusitec fermenter content with or without addition of malic acid

\begin{tabular}{|c|c|c|c|c|c|c|c|}
\hline \multirow[b]{2}{*}{ Fatty acid $(n=6)^{1}$} & \multicolumn{3}{|c|}{ Treatment $^{2}$} & \multirow[b]{2}{*}{ SEM } & \multicolumn{3}{|c|}{$P$-value } \\
\hline & Control & Trt1 & Trt2 & & $\operatorname{Trt}^{3}$ & $\operatorname{samT}^{4}$ & $\operatorname{Trt} \times \operatorname{sam} \mathrm{T}^{5}$ \\
\hline C6:0 & 2.19 & 2.10 & 1.87 & 0.30 & 0.0729 & 0.5324 & 0.0078 \\
\hline C8:0 & 2.07 & 2.18 & 1.92 & 0.24 & 0.7338 & 0.0180 & 0.1937 \\
\hline C10:0 & 3.99 & 4.13 & 3.50 & 0.31 & 0.1459 & 0.0092 & 0.1830 \\
\hline C12:0 & 2.74 & 2.98 & 2.41 & 0.56 & 0.1351 & 0.0700 & 0.2724 \\
\hline C14:0 & 5.19 & 5.08 & 4.86 & 0.49 & 0.5283 & 0.3869 & 0.6745 \\
\hline C15:0 & 2.05 & 1.93 & 2.19 & 0.04 & 0.3862 & 0.0222 & 0.5994 \\
\hline C16:0 & 22.39 & 21.97 & 22.58 & 1.12 & 0.9260 & 0.7437 & 0.3115 \\
\hline C18:0 & 17.71 & 20.04 & 17.32 & 2.24 & 0.4441 & 0.0475 & 0.0017 \\
\hline cis-9 C18:1 & 4.92 & 4.76 & 4.85 & 0.26 & 0.9084 & 0.2522 & 0.1065 \\
\hline trans-11 C18:1 (vaccenic acid) & 4.51 & 4.38 & 4.46 & 0.87 & 0.3231 & 0.0009 & 0.0816 \\
\hline cis-9, trans-11 conjugated linoleic acid & 2.39 & 2.12 & 2.23 & 0.17 & 0.6543 & 0.1923 & 0.3149 \\
\hline C18:3 & 1.23 & 1.18 & 1.21 & 0.08 & 0.6593 & 0.0852 & 0.4726 \\
\hline cis -9, cis -12 C18:2 & 2.29 & 2.19 & 2.34 & 0.11 & 0.1741 & 0.0004 & 0.3881 \\
\hline C22:6 (docosahexaenoic acid) & 11.85 & 11.20 & 12.91 & 1.12 & 0.1629 & $<0.0001$ & 0.0334 \\
\hline
\end{tabular}

${ }^{1} \mathrm{n}=$ number of samples in each mean.

${ }^{2}$ Trt1 = control diet with $10 \mathrm{~m} M$ malic acid; Trt2 = control diet with $20 \mathrm{~m} M$ malic acid.

${ }^{3}$ Trt $=$ experimental treatment.

${ }^{4}$ sam $\mathrm{T}=$ sampling time.

${ }^{5}$ Trt $\times$ sam $\mathrm{T}=$ interaction of treatment and sampling time.

The reasons that the results from our study may be opposite our theoretical deductions are unclear. In the present experiment, the change in FA concentration in the fermenter contents across sampling times was consistent with the results of Váradyová et al. (2007). Interestingly, we found that the changes in some FA (C8:0, C10:0, trans-11 C18:1, cis-9, cis-12 C18:2, C22:6) across sampling times were different among treatments $(P<0.05)$, but the interaction of treatment and sampling time did not exert an obvious effect, except for $\mathrm{C} 22: 6$ and $\mathrm{C} 18: 0$, for which the reason was unclear. In summary, our results indicated that malic acid had no effect on VA accumulation and a decrease in stearic acid in the fermenter contents.

\section{ACKNOWLEDGMENTS}

This work was funded in part by the Ministry of Science and Technology of the P. R. China (2006BAD12B03 and 2006DFB32160, respectively). The authors thank the staff of the ruminant nutrition laboratory at the Institute of Animal Science, Chinese Academy of Agricultural Science, for their assistance. We also acknowledge the kind contribution of A. F. Kertz to this work.

\section{REFERENCES}

AbuGhazaleh, A. A., and B. N. Jacobson. 2007. The effect of $\mathrm{pH}$ and polyunsaturated C18 fatty acid source on the production of vaccenic acid and conjugated linoleic acids in ruminal cultures incubation with docosahexaenoic acid. Anim. Feed Sci. Technol. 136:11-22.
AbuGhazaleh, A. A., and T. C. Jenkins. 2004. Disappearance of docosahexaenoic and eicosapentaenoic acids from cultures of mixed ruminal microorganisms. J. Dairy Sci. 87:645-651.

AbuGhazaleh, A. A., M. B. Riley, E. E. Thies, and T. C. Jenkins. 2005. Dilution rate and $\mathrm{pH}$ effects on the conversion of oleic acid to trans $\mathrm{C} 18: 1$ positional isomer in continuous culture. J. Dairy Sci. 88:4334-4341.

Belury, M. A. 1995. Conjugated dienoic linoleate: A polyunsaturated fatty acid with unique chemoprotective properties. Nutr. Rev. 53:83-89.

Bu, D. P., J. Q. Wang, T. R. Dhiman, and S. J. Liu. 2007. Effectiveness of oils rich in linoleic and linolenic acids to enhance conjugate linoleic acid in milk from dairy cows. J. Dairy Sci. 90:9981007.

Callaway, T. R., and S. A. Martin. 1996. Effects of organic acid and monensin treatment on in vitro mixed ruminal micro-organisms fermentation of cracked corn. J. Anim. Sci. 74:1982-1989.

Carro, M. D., and R. J. Ranilla. 2003. Effect of addition of malate on in vitro rumen fermentation of cereal grains. Br. J. Nutr. 89:181-188

García-Martínez, R., M. J. Ranilla, M. L. Tejido, and M. D. Carro. 2005. Effects of disodium fumarate on in vitro rumen microbial growth, methane production and fermentation of diets differing in their forage:concentrate ratio. Br. J. Nutr. 94:71-77.

Gomez, J. A., M. L. Tejido, and M. D. Carro. 2005. Influence of disodium malate on microbial growth and fermentation in rumen-simulation-technique fermenters receiving medium- and high-concentrate diets. Br. J. Nutr. 93:479-484.

Harfoot, C. G., and G. P. Hazlewood. 1997. Lipid metabolism in the rumen. Pages 382-426 in The Rumen Microbial Ecosystem. 2nd ed. P. N. Hobson and D. S. Stewart, ed. Chapman and Hall, London, UK.

Jenkins, T. C., R. J. Wallace, P. J. Moate, and E. E. Mosley. 2008. Board-Invited Review: Recent advances in biohydrogenation of unsaturated fatty acids within the rumen microbial system. J. Anim. Sci. 86:397-412.

Kramer, J. K. G., V. Fellner, M. E. R. Dugan, F. D. Sauer, M. M. Mossoba, and M. P. Yurawecz. 1997. Evaluating acid and base catalysts in the methylation of milk and rumen fatty acids with special emphasis on conjugated dienes and total trans fatty acids. Lipids 32:1219-1228. 
Kramer, J. K. G., and J. Zhou. 2001. Conjugated linoleic acid and octadecenoic acids: Extraction and isolation of lipids. Eur. J. Lipid Sci. Technol. 103:594-632.

Latham, M. J., J. E. Storry, and M. E. Sharpe. 1972. Effects of lowroughage diets on the microflora and lipid metabolism in the rumen. Appl. Microbiol. 24:871-877.

Martin, S. A. 1998. Manipulation of ruminal fermentation with organic acids: A review. J. Anim. Sci. 76:3123-3132.

Martin, S. A., G. Fonty, and B. Michalet-Doreau. 2002. Factors affecting the fibrolytic activity of the digestive microbial ecosystems in ruminants. Pages 1-17 in Gastrointestinal Microbiology in Animals. S. A. Martin, ed. Research Signpost, Trivandrum, India.

Martin, S. A., and T. C. Jenkins. 2002. Factors affecting conjugated linoleic acid and trans-C18:1 fatty acid production by mixed ruminal bacteria. J. Anim. Sci. 80:3347-3352.

McDougall, E. I. 1948. Studies on ruminant saliva. I. The composition and output of sheep's saliva. Biochem. J. 43:99-109.

Newbold, C. J., S. López, N. Nelson, J. O. Ouda, R. J. Wallace, and A. R. Moss. 2005. Propionate precursors and other metabolic intermediates as possible alternative electron acceptors to methanogenesis in ruminal fermentation in vitro. Br. J. Nutr. 94:27-35.

Parodi, P. W. 1997. Cow's milk fat components as potential anticarcinogenic agents. J. Nutr. 127:1055-1060.
Piperova, L. S., J. Sampugna, B. B. Teter, K. F. Kalscheur, M. P. Yurawecz, Y. Ku, K. M. Morehouse, and R. A. Erdman. 2002. Duodenal and milk trans octadecenoic acid and conjugated linoleic acid (CLA) isomers indicate that postabsorptive synthesis is the predominant source of cis-9-containing CLA in lactating dairy cows. J. Nutr. 132:1235-1241.

Scollan, N. D., M. S. Dhanoa, N. J. Choi, W. J. Maeng, M. Enser, and J. D. Wood. 2001. Biohydrogenation and digestion of long chain fatty acids in steers fed on different sources of lipid. J. Agric. Sci. 136:345-355

Shingfield, K. J., S. Ahvenjarvi, V. Toivonen, A. Arola, K. V. V. Nurmela, P. Huhtanen, and J. M. Griinari. 2003. Effect of dietary fish oil on biohydrogenation of fatty acids and milk fatty acid content in cows. Anim. Sci. 77:165-179.

Turpeinen, A. M., M. Mutanen, A. Aro, I. Salminen, S. Basu, D. L. Palmquist, and J. M. Griinari. 2002. Bioconversion of vaccenic acid to conjugated linoleic acid in humans. Am. J. Clin. Nutr. 76:504-510.

Ungerfeld, E. M., S. R. Rust, and R. Burnett. 2003. Use of some novel alternative electron sinks to inhibit ruminal methanogenesis. Reprod. Nutr. Dev. 43:189-202.

Váradyová, Z., S. Kišidayov, P. Siroka, and D. Jalč. 2007. Fatty acid profiles of rumen fluid from sheep fed diets supplemented with various oils and effect on the rumen ciliate population. Czech. J. Anim. Sci. 52:399-406. 